\title{
On the Distinction between Convergent and Linked Arguments
}

\author{
DAVID A. CONWAY University of Missouri-St. Louis
}

Key Terms: Convergent arguments; linked arguments.

\begin{abstract}
Most recent writers of informal logic texts draw a distinction between "linked" and "convergent" arguments. According to its inventor. Stephen Thomas, the distinction is of the utmost importance; it "seems crucial to the analysis and evaluation of reasoning in natural language." I argue that the distinction has not been drawn in any way that makes it both clear and of any real originality or importance. Many formulations are obscure or conceptually incoherent. One formulation of the distinction does seem tolerably clear and I develop another, but neither promises to make it matter much. We can well do without it.
\end{abstract}

Most recent writers of informal logic texts draw a distinction between "linked" and "convergent" arguments. The intuitive idea behind the distinction is that the premises of some (linked) arguments support their conclusions "in a united or combined way," while in other (convergent) arguments "each reason supports the conclusion completely separately and independently of the other."' Using the usual diagramming technique in which each arrow can be read as "therefore," here is a case in which our intuitions go the first way:

\section{Smoking marijuana is + I should not break against the law.}

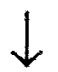

I should not smoke marijuana.

In the following, the premises seem separately to support the conclusion:
I promised Harry that

I would go into partnership with him.

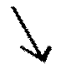

If I go into partnership with Harry, I will make a lot of money.

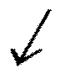

I should go into partnership with Harry. ${ }^{3}$

According to its inventor, Stephen Thomas, the linked/convergent distinction is of the utmost importance; it "seems crucial to the analysis and evaluation of reásoning in natural language." Monroe Beardsley's earlier attempt to analyze arguments in natural language could not "be generally applied at all" because it lacked this "crucial" distinction. ${ }^{5}$

Despite its intuitive appeal and current popularity, I doubt that the distinction can be drawn in any way that makes it both clear and of any real originality or importance. Many formulations of the distinction are obscure or conceptually incoherent. One formulation does seem tolerably clear and I will develop another, but neither promises to make the distinction matter much, We can well do without it.

\section{2}

Some explanations of the distinction are suggestive but too unclear (too vague, metaphorical, etc.) to be of much real use. John Eric Nolt says that arguments are linked when the premises work in conjunction, rather than separately, in support of the conclusion. ${ }^{6}$ In linked arguments, according to Thomas, each premise "is helped by the others to support the conclusion."7 We know how people 
building a house or huskies pulling a sled can work in conjunction or help one another, but how do such "inert" things as premises do so?

Robert J. Yanal tells us that the reasons in "dependent" (linked) arguments are in the same line of thought; reasons in "independent" (convergent) arguments are not in the same line of thought. ${ }^{8}$ This is indeed suggestive, but our vague ideas about what it might mean are shattered when Yanal says "it is important to remember that" convergent arguments, those whose premises are "not in the same line of thought," may still have premises that are "linked conceptually."9 If premises can be "not in the same line of thought" but still "linked conceptually," do we have any idea at all what it means to be or not to be "in the same line of thought"?

When we look carefully at some other formulations of the distinction, our reaction is likely to be: "Surely this is not what the authors really mean to say." Yanal, for instance, also says that arguments are linked when their reasons "fill in each other's logical gaps (i.e., support each other)"; otherwise, arguments are convergent. ${ }^{10}$

We cannot take this literally because reasons do not themselves have "logical gaps." And the requirement for linked arguments certainly cannot be that the premises "support each other," as if

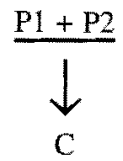

is the correct diagram for an argument only if also

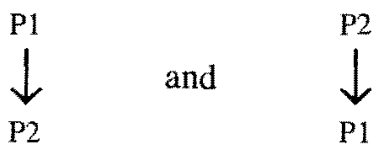

Probably what is meant here has to do with "logical gaps" between premises and a conclusion and premises "supporting each other" in closing those gaps. But again the formulation seems at best unhelpful. For to say there are "logical gaps" between some premises and a conclusion means that it is possible for those premises to be true and the conclusion false. Should every additional premise that makes the falsity of the conclusion less likely (makes the gap "smaller") be diagrammed as linked? Then only additional premises that do not succeed in really adding support for the conclusion would be diagrammed as convergent, which is, presumably, not what is meant. To say, instead, that linked premises are those that do not just close the gap but "support each other" in closing the gap is no advance on the previous vague formulations in terms of "working together" and being "in the same line of thought."

Here is another of Thomas's formulations:

[1]f each reason alone would be enough, if true, to support the conclusion, and if the falseness of one reason would not weaken a step of reasoning from the other to the conclusion, then the reasoning can be diagrammed as convergent. But if the falseness of a reason would weaken the step from the other(s) to the conclusion, then link that reason together with the other(s) in the diagram. ${ }^{11}$

This apparently means that if $P 1$ and $P 2$ are offered in support of $C$, each does support $C$, and $P I$ when taken alone supports $C$ as much as it- $(P I)$-does when conjoined with $P 2$ ( $P 2$ does not add to the support $P 1$ gives to $C$ ), the reasoning is convergent.

To apply this principle, we must compare the amount of support $P 1$ gives to $C$ in

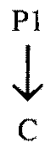

to the amount of support $\mathrm{P} 1$ gives to $\mathrm{C}$ in

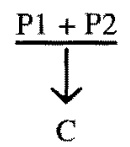


But what does it mean to ask how much P1 supports $\mathrm{C}$ in the second case? How much does the conditional support the conclusion in a case of modus ponens? Consider the argument: "Gerbils are a lot like hamsters and hamsters make good pets. So gerbils make good pets." How much does each premise support the conclusion? I doubt that these questions have a sense, and so that this formulation of the distinction has a sense.

Alec Fisher puts the distinction this way:

If several reasons are given for some conclusion there are two possibilities: the reasons may be presented as jointly supporting the conclusion (taken together they support the conclusion but each in isolation does not [linked]) or they may be presented as independently [convergently] justifying it (so that if you accept one of the reasons the author expects you to accept the conclusion) ${ }^{12}$

\section{But consider this argument:}

(1) Yesterday I saw a frog in my garden and it was green.

(2) Today I saw a frog in my garden and it was green.

(C) All the frogs in my garden are green.

Since each premise alone supports the conclusion, the argument does not meet Fisher's criterion for being joint (linked). And since neither premise independently justifies (or is offered as independently justifying) the conclusion, it also does not meet his criterion for independent (convergent) support. Fisher's account of the supposedly exhaustive distinction between independent and joint support will not account for the frog case or for any other whose premises are independently relevant to its conclusion but individually fail to justify it.

The frog generalization is neither convergent nor linked on Fisher's account. It could be both given yet two other of Thomas's various formulations. When "each reason supports the conclusion com- pletely separately and independently of the other, the reasoning is convergent." 13 "If neither reason needs the other reason (or anything like the other) in order to support the conclusion, then the reasoning can be diagrammed as convergent reasoning."14 Thomas offers as illustration the argument about going into partnership with Harry, but the generalization about the frogs in my garden would seem to fit the formulation just as well. Each observation of a frog, taken alone, gives some support for the conclusion.

But Thomas quite specifically says that statistical generalizations should be diagrammed as linked, because "the strength of support is much greater when the instances are considered in union together." ${ }^{15}$ The criterion of convergence is no longer that each premise individually supports the conclusion, which would make generalizations convergent. Rather it is the very different one that each premise individually supports the conclusion and the degree of support given by the premises considered together is not (or not much?) greater than the degree of support given by the premises considered individually, which makes generalizations linked. It cannot be both ways.

\section{3}

The last problem we found with Thomas was that he runs together two different sets of criteria for the distinction. Perhaps one or the other of those might be satisfactory by itself.

Several authors consistently hold that convergent arguments are those in which the premises individually provide some support for the conclusion. Trudy Govier puts this in terms of relevance. Support is linked when

the premises depend on each other. One premise could not lend the conclusion any support without the others... In arguments with convergent support, each premise is 
quite separately relevant to the conclusion and would count as a reason in support of the conclusion, even if the other converging premises were false. ${ }^{16}$

Let us call this the relevance criterion for the convergentlinked distinction. Putting it as diagramming instruction, it is simply and clearly stated in a few lines: Premises that are individually relevant to a conclusion are to be diagrammed as providing convergent support for that conclusion. Premises that are relevant to a conclusion only when conjoined are to be diagrammed as linked. ${ }^{17}$

The relevance criterion, however, does not capture whatever it is that is intuitively plausible in the distinction. Many arguments that are intuitively linked would become convergent on this criterion. And we cannot assess these arguments as convergent-assess the separate lines of support for a conclusion and somehow use the results to arrive at an overall evaluation-with any hope of reaching a correct overall evaluation. ${ }^{18}$

Consider some cases:

Nadine lays eggs. Nadine suckles her young. So Nadine is a platypus. ${ }^{19}$

Each premise is relevant to the conclusion, but they are not intuitively separate the way the premises of the partnership example are. And since each taken alone gives only the smallest degree of support to the conclusion, we cannot "combine" that support and get the correct result that the premises give rather strong support to the conclusion. (Nadine could only be a platypus or a spiny anteater.)

We do not need to look to exotic animals to find such examples. The best candidate for the philosophy position at Northern University will be a specialist both in medieval philosophy and in contemporary modal logic. There are specialists in each of these fields but there may not be many who are expert in both. So to evaluate
Harvey is specialist in medieval philosophy. Harvey has a specialization in contemporary modal logic. So Harvey is the best candidate for the philosophy position at Northern University.

we have to consider the degree of support the two premises taken together give the conclusion.

Many of our most everyday bits of reasoning show that individually relevant premises cannot be considered independently.

The wind is picking up. The clouds are thickening. It is getting cold. Surely it will snow before dawn.

Here each factor is relevant to the conclusion that it will snow, but no one of them gives much support. The factors together make a stronger case than any "combination" of their individual degrees of support.

Diagramming individually relevant premises as convergent and then evaluating them independently will even lead to missing some valid inferences.

She is either in the living room or in the bedroom. She is not in the living room. So she is in the bedroom.

The first premise taken alone is obviously relevant to the conclusion (making it $50 \%$ likely). And any information that something is not in some one place increases, however slightly, the likelihood that it is in some other particular place. So the second premise is also relevant to the conclusion. Evaluating the argument by "combining" these degrees of support gives a starkly wrong result, since the premises taken together give a valid argument. ${ }^{20}$

In sum, if individual relevance of premises is the criterion for convergence, the distinction does not correspond to whatever intuitions we might have about "separateness" of premises. Further, an argument being convergent on this criterion cannot serve as an "instruction" to evaluate each line of support separately or to evaluate the degree of support of the premises 
for the conclusion in any other particular way. So if there is any evaluative importance to the linked/convergent distinction, understood in this way, it is not in the area of the degree of support premises give to a conclusion. We will look again at the relevance criterion in section 8 .

\section{4}

Before considering Thomas's suggestion that statistical generalizations should be diagrammed as linked, because "the strength of support is much greater when the instances are considered in union together,"21 let us think how we should evaluate strength of support. Remarkably, most who claim that the linked/ convergent distinction is important for evaluation say nothing about how to evaluate convergent arguments. Clearly we cannot simply add the degrees of support of the separate lines.

Twenty witnesses say Herbert confessed to Herbert robbed the bank. robbing the bank.
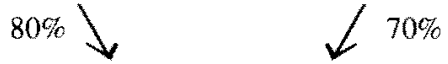

Herbert robbed the bank.

Adding the degrees of support will give a total of over $100 \%$ which does not make sense.

According to Nolt, the "reasoning of a [convergent] argument will generally be as strong as the strongest chain of reasoning it contains." 22 This is his only example: $:^{23}$

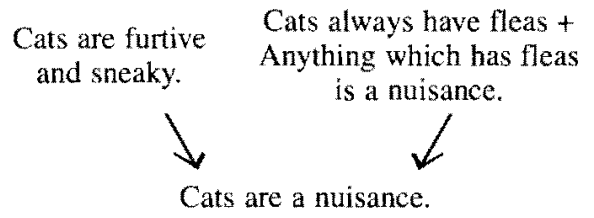

Since the inference on the right is valid, the argument as a whole is valid, according to Nolt's way of evaluating.

This is the correct evaluation, but it is hard to think of a procedure that would not give the correct one in this sort of case. Before there was diagramming, if we were given these premises in support of this conclusion, we would have written the argument in standard form.

1. Cats are furtive and sneaky.

2. Cats always have fleas.

3. Anything which has fleas is a nuisance.

4. Cats are a nuisance. $1,2,3$

We would have known that the argument is valid, because if (2) and (3) are true, then (4) will be true, and so if (2), (3), and (1) are true, then (4) will be true.

Consider some other cases that intuitively seem convergent.
I dreamt that the Bears will win the 1999

Super Bowl + Exactly $80 \%$ of my football dreams come true.

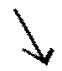

My mother told me that the Bears will win the 1999 Super Bowl +

Exactly $60 \%$ of $\mathrm{my}$

mother's football predictions are correct.

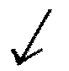

The Bears will win the 1999 Super Bowl.

Using Nolt's way of evaluating, we should take the conclusion to be $80 \%$ likely. But why shouldn't we instead conclude that my mother's predictions, which are wrong $40 \%$ of the time, take precedence?

Nor does Nolt's procedure seem to give the correct result in these cases:

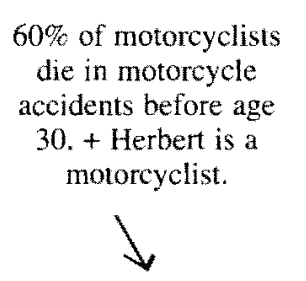

Herbent will die before age 30 .
$70 \%$ of people who smoke 8 packs of unfiltered cigarettes a day die of lung disease before age $30 .+$ Herbert smokes 8 packs a day.

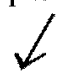

Nolt's method of "totaling" would pick the inference on the right and conclude that, relative to all of the premises, it is $70 \%$ probable that Herbert will die before age 30. But this looks wrong. For Herbert's smoking alone makes it $70 \%$ likely that he will die before 30 . Surely the perilous motorcycling could have some further effect on the likelihood of his early death. Normally, we would expect that the motorcycle 
riding is an additional threat to Herbert and that it, given his smoking, would make his early demise more than $70 \%$ likely. ${ }^{24}$

Here is a similar but even simpler case. A person shot at by two entirely independent sharpshooters, each of whom usually hits her target, is at greater risk than someone being shot at by only one of the sharpshooters.

Sharpshooter A will shoot at Herman one time + She hits her target $80 \%$ of the time.

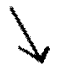

Herman will be shot.

This argument suggests another way of "totaling" the degree of support separate inferences give a conclusion.

If Herman is lucky, his will be one of the twenty cases of every hundred in which $A$ is inaccurate. Still, since B is $90 \%$ accurate, in 18 of those 20 cases B's bullet can be expected to hit Herman. ${ }^{25}$ So the overall chance of Herman being shot (hit by at least one bullet) is $98 \%$. We cannot get this answer using Nolt's method of taking the overall degree of support to be the degree of support of the strongest inference to the conclusion.

\section{5}

If Yanal is correct, the "sharpshooter method" will always be the correct one for "totaling" the separate degrees of support in a convergent argument. Consider an argument that would be diagrammed as

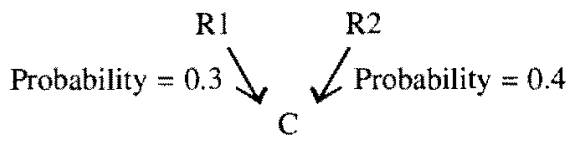

Here,

certainty can be thought of as 1.0 probability..., merely knowing that $R l$ is true leaves us with $0.7(=1.0-0.3)$ of

uncertainty. Now, when $R 2$...is brought forward, we have decreased our uncertainty by 0.4 . We now know 0.4 times 0.7 , or 0.28 more than we knew before. In total, we know the conclusion with 0.3 (the probability of $R I$ ) plus 0.28 (the probability of $R 2$ times the remaining "unknown" left over from 0.3 ), which equals $0.58 .^{26}$

But the sharpshooter method also cannot be relied on to give correct evaluations of apparently separate lines of support.

Harvey handles cobras barehanded $+80 \%$ of people who handle cobras barehanded die young.

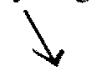

Harvey will die young.

As in the smoking/motorcycle case, the sharpshooter method's answer would be that it is $98 \%$ likely that Harvey will die young. But this ignores too many possibilities: perhaps drinking antifreeze daily makes one completely or partially immune to the effects of cobra venom, so that those who both handle cobras and drink antifreeze are at lower or no risk; perhaps any antifreeze drinker dies instantly on contact with a cobra. ${ }^{27}$ Given the premises telling us that Harvey both handles snakes and drinks antifreeze for breakfast, what we need to know to evaluate the likelihood of the conclusion is something like

\section{$\mathrm{X} \%$ of those who both handle snakes and drink antifreeze for breakfast die young.}

And this sort of information is not $a$ function of the premises about snakehandling and antifreeze-drinking taken independently.

The sharpshooter method seems to give the right result about the likelihood of Herman being shot, but it does so only insofar as we are making the natural assumption that the sharpshooters are independent of one another in every respect. Suppose that sharpshooter A misses every target that B misses. In that 
case, A will pose no additional threat to Herman, and he stands no more than the $90 \%$ chance of being shot. And in the motorcycle/smoking case, motorcycle riding may actually decrease smoker Herbert's chances of dying before age 30 . The clean outdoor air in cyclists' faces might cleanse the lungs, erase any threat of lung disease, and leave only the $60 \%$ chance of dying on his cycle.

Let's amend the motorcycle case a bit.

$60 \%$ of motorcyclists die before age $30+$ Herbert rides a motorcycle.

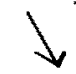

Herbert will die before age 30 .

The example is different now, since the causes of death are not specified. Using the sharpshooter method of evaluating the likelihood of Herbert's death before age 30 , the calculation would be $[.6+(.7 \times .4)$ $=.88$ ].

But, again, there is no reason to think that this is a correct evaluation. Maybe

a) most or even all of the smokers who die before 30 ride motorcycles and perish on their cycles.

Now the left arrow does not represent an additional threat to Herbert, the smoker/ cyclist. Maybe

b) most or even all of the motorcyclists smoke 8 packs a day and die before 30 of lung disease.

In this case, the right arrow does not represent an additional threat to Herbert, the cyclist/smoker.

Here are some other possibilities that are compatible with the premises:

c) All smokers are cyclists. ${ }^{28}$

\begin{tabular}{|c|c|}
\hline Smokers & Cyclists \\
$70 \%$ die before 30 & $60 \%$ die before 30 \\
\hline
\end{tabular}

Here, Herbert's chances of dying, of whatever cause, before 30 are $70 \%$. d) All cyclists are smokers.

\begin{tabular}{|cc|}
\hline $\begin{array}{c}\text { Cyclists } \\
60 \% \text { die before } 30\end{array}$ & Smokers \\
$70 \%$ die before 30 \\
\hline
\end{tabular}

Now Herbert's chances of early death are $60 \%$.

e) Only Herbert is both a smoker and a cyclist.

We may conjecture that smoking and cycling are independent threats (smokers dying of smoking, cyclists from cycling) and "total" in the sharpshooter manner. But nothing in the argument justifies this conjecture. And even if we were to make it, the problems noted before come into play: maybe cycling cleanses the lungs, etc.

f...) $50 \%$ of smokers are also cyclists... $80 \%$ are.. $.90 \%$.

Each of these can make a difference to the overall likelihood that Herbert dies young.

With all of these possibilities, it would be naive to assume that the sharpshooter method will correctly "total" the intuitively separate lines of support for the conclusion about Herbert's early demise.

\section{6}

While the sharpshooter method cannot be counted on to correctly "total" intuitively separate amounts of support, in some cases (as when it is given that the sharpshooters are completely independent), it does do so. With this in mind, we can look at Thomas's suggestion that statistical generalizations should be diagrammed as linked, because "the strength of support is much greater when the instances are considered in union together." 29 This accords with Yanal's formulation of the way "to present the real distinction between convergent and linked reasons in principle": 30

Reasons are DEPENDENT [linked] when together they make the overall 
strength of the argument $M U C H$ GREATER than they would considered separately.... Reasons are INDEPENDENT [convergent] when together they DO NOT make the overall strength of the argument much greater than they would considered separately. ${ }^{31}$

To identify an argument as convergent or linked using this definition we

(a) determine the total amount of support the premises considered separately give the conclusion, using the sharpshooter method;

(b) determine the amount of support the premises considered together give the conclusion;

(c) take the amount in (a) to be the actual amount of support the premises give the conclusion unless the amount of support in (b) is greater, in which case (b) gives the actual amount;

(d) if the actual amount of support is as given in (a), diagram the argument as convergent; if the actual amount of support is as given in (b), diagram the argument as linked.

In short, an argument is convergent, and properly evaluated by the sharpshooter method, unless considering the premises together gives more support for the conclusion. Roughly (disregarding "ties"), this means that we should diagram and evaluate the argument in whichever way gives the greater amount of support for the conclusion.

Let us call this the Yanal criterion for evaluating arguments.

If we adopt the Yanal criterion, we cannot analyze arguments as linked or convergent before we evaluate them. Now the classification is a result of the evaluative work. ${ }^{32}$ So any idea that we need the distinction in order to know how to evaluate arguments is essentially abandoned. More important, unless we restrict our attention to the simplest cases (considering the premises of an instance of modus ponens together will give more support than considering them separately), carrying out these steps is either impossible or not to be counted on to give the correct result.

Look at an earlier example:
Harvey handles cobras barehanded $+80 \%$ of people who handle cobras barehanded die young.

Harvey will die young.
Harvey drinks antifreeze for breakfast + $90 \%$ of people who drink antifreeze for breakfast die young.

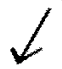

Following step (a), we evaluate the argument by the sharpshooter method, finding the conclusion to be $98 \%$ likely. We know this may not be the right answer (the sharpshooter method does not always give the right answer), but we are not done yet. Steps (b) through (d) are supposed to supply a sort of corrective for the cases when we should not analyze and evaluate premises as convergent. So going on to step (b), we consider the amount of support the premises all considered together give the conclusion. But this is just what we don't know: how likely it is that Harvey dies young given that he both handles cobras and drinks antifreeze.

Perhaps we should look outside the argument itself for any connection between handling cobras and drinking antifreeze. Suppose we find out that antifreeze is a mildly effective cobra antivenom, and that

(A) $60 \%$ of those who both handle cobras barehanded and drink antifreeze for breakfast die young.

To consider the given premises together (Harvey both handles cobras and drinks antifreeze) we should take (A) into account.

So now we have to compare
Harvey handles cobras barehanded $+80 \%$ of people who handle cobras barehanded die young.

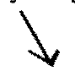

Harvey drinks antifreeze for breakfast + $90 \%$ of people who drink antifreeze for breakfast die young.
Harvey will die young. 
to

Harvey handles cobras barehanded $+80 \%$ of people who handle cobras barehanded die young + Harvey drinks antifreeze for breakfast $+90 \%$ of people who drink antifreeze for breakfast die young $+60 \%$ of those who both handle cobras barehanded and drink antifreeze for breakfast die young.

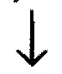

Harvey will die young.

Since this makes the conclusion just $60 \%$ likely (the second and fourth premise dropping out as irrelevant), it does not make the conclusion more likely than does the convergent evaluation. Following (c), then, we take the convergent evaluation (and so the analysis) as the correct one. This is clearly a mistake.

Not only does the analysis give the wrong result in such a case; the entire comparison is misguided. For while we are supposedly comparing the amount of support sets of premises considered separately give a conclusion to the amount of support they give it considered together, we are really comparing the original sets of premises, considered separately, to the original premises plus $(A)$ considered together. We are not comparing the amounts of support some premises considered in different ways give a conclusion but the amount of support two different sets of premises give a conclusion.

To avoid this problem we could add (A) to the original set of premises when we consider them separately. Then we have this to evaluate:

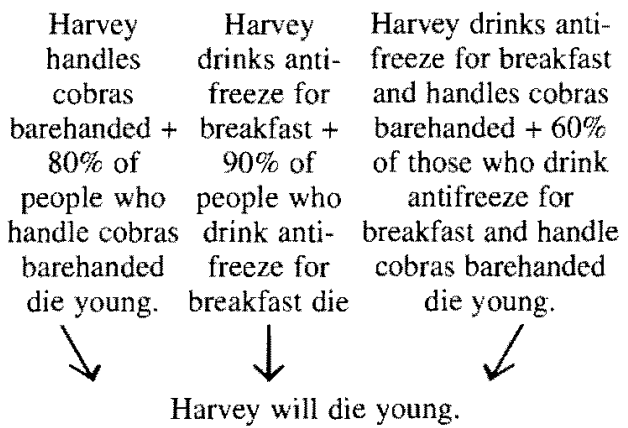

The sharpshooter method gives a likelihood of $99.2 \%$ to the conclusion ${ }^{33}$ Since linking the premises gives a total support of only $60 \%$, we have to adopt $99.2 \%$ as the correct amount of support and diagram the argument as convergent. Again we have the wrong answer. But surely we already knew we would not get a sensible evaluation from applying the sharpshooter method to this conglomeration of premises.

Thus, despite its apparent simplicity and correctness in cases like modus ponens, in many other cases applying the Yanal criterion is difficult, nonsensical, or just gives the incorrect evaluation and analysis of the argument.

\section{7}

Why do we really consider the premises of a case of modus ponens together rather than separately? We do not have to say it is because they "work together," or are in "the same line of thought," or "they give more support to the conclusion that way." It is because we get the right answer that way. "If today is February 29 , this is a leap year. Today is February 29 . So this is a leap year." Neither premise by itself is even relevant to the conclusion, and so the "total" of their separate support is nil. But that is the wrong answer. We know what the right answer is: the premises cannot be true and the conclusion false, so the argument is valid. The "degree of support" is $100 \%$.

This suggests a way of making a linked/convergent distinction that is in some respects similar to the Yanal procedure:

(a) consider how the premises relate to one another and to the conclusion. For instance, do the premises "overlap" as in one of the smoking/cycling arguments? Could they undermine one another as in the cobra/antivenom case? Is the argument valid? Is it a statistical syllogism? An 
inductive generalization?... Or can these premises in relation to this conclusion be counted on to "total" correctly using the sharpshooter method?

(b) If the answer to the last question is yes, diagram the argument as convergent. Otherwise diagram it as linked.

In shortest form, arguments are convergent if and only if they correctly "total" by the sharpshooter method. Let us call this the real criterion.

I suspect that the real criterion captures as well as possible any intuitive sense behind the notion of convergent arguments.

But understood in this way, the notion doesn't have the importance it seemed to promise. In convergent arguments the premises (or subsets of them) were to be related to conclusions in a very special way, independently of one another. We could analyze arguments, determine that this special relationship holds, and then (and only then) separately assess the independent lines of support, arriving at the correct evaluation of the overall degree of support for the premises.

But it is now apparent that we can never simply "read off" from the content of an argument that it is convergent. No matter how unrelated the premises may appear, we cannot ever assume that they correctly total by the sharpshooter method. ${ }^{34}$ Rather we have to follow step (a), considering how the premises relate to the conclusion and to each other, i.e., consider them together. The cobra/antifreeze example, the cycle/smoking example, and the sharpshooter case itself show this. Even Thomas's most apparent instance of convergent reasoning may not correctly total convergently.

I promised Harry that

I would go into partnership with him.

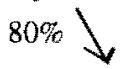

I should go into partnership with Harry.
This is convergent only on the assumption that promise-keeping and money-making do not "interact" in some way. And we do not know that from anything in the argument. (It would not even be a great distortion of some ethical theories to suggest that, while both promise-keeping and money-making are desirable, any virtue there is in keeping a promise is nullified when doing so leads to material gain.)

Here is a case Yanal presents as clearly convergent: ${ }^{35}$

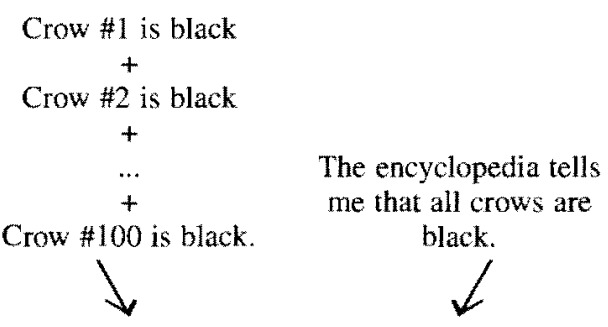

All crows are black.

Whether this is really convergent (properly sums by the sharpshooter method) depends on how the generalization on the left relates to the premise on the right. It could be that my observations of birds are not so reliable, and my encyclopedia is old and sometimes inaccurate, but almost every time my aviary observations agree with the aged encyclopedia's claims the accuracy rate is near $100 \%$ (a much greater amount of support than we would get by the sharpshooter method). Or it could be that almost every time my observations agree with the encyclopedia the encyclopedia is incorrect.

Thus, even when premises apparently are entirely unrelated or "in a different line of thought," we have to look at how they might relate to one another and to the conclusion in order to know whether they "total" by the sharpshooter method and so whether the argument should be diagrammed as convergent. To do this is to do much of the work of evaluation. And it requires careful consideration of how the premises relate to each other and how they 
all together support the conclusion. We cannot first determine that an argument is convergent (and so to be diagrammed with separate arrows) and therefore know that we do not need to consider the premises together in order to evaluate properly the strength of the support for the conclusion.

Is it nonetheless worth showing in a diagram that an argument properly "totals" by the sharpshooter method? The premises of some arguments "total" by the principles of the propositional calculus or by quantification rules. The premises of other arguments "total" by putting together facts and applying Bayes' theorem. Still others rely on more imprecise principles about the strength of analogies or generalizing from instances. And, in some cases, premises "total" by the sharpshooter method. Is the difference between evaluating by the sharpshooter method and by quantification theory any more basic than the difference between evaluating by truth tables and by the generalization techniques of polling experts or by the rules of evidence in a courtroom, or by any other method appropriate to a given argument? To elevate only the former difference to a fundamental distinction between types of arguments seems, at best, a misleading bit of hyperbole.

It is, however, the only one of these distinctions that can be naturally shown by so simple an expedient as removing the plus sign from the premises in a diagram. This by itself may go far toward accounting for the pervasiveness of the linked/convergent distinction.

\section{8}

Perhaps we should not give up quite yet on finding some important rationale for the distinction. Thomas suggests we need the notion of a convergent argument because to refute the justification [given by a convergent argument], each of the different lines of reasoning must be dealt with and refuted separately (so that it is not enough for an opponent merely to show that one of the basic reasons is false). ${ }^{36}$

The implication seems to be that if an argument is not convergent showing one of the premises to be false must mean rejecting the entire argument. Thus, without the notion of convergence, we would have to reject many arguments that should not be rejected.

This is all myth. Even when premises clearly "work together," we know perfectly well that the falsity of one need not necessitate rejecting the entire argument. Consider again the nonconvergent reasoning in a generalization: If I think that I have seen a great many frogs in my garden and each one is green, the falsity of "Last Wednesday I saw a frog in my garden and it was green" does not mean rejecting the conclusion "All the frogs in my garden are green." It just means that the report of this particular observation should not be included in the premises supporting the conclusion. (The falsity of "Last Wednesday I saw a frog in my garden and it was green" does not entail "I saw a frog and it was not green." Thomas seems to think that the failure of a confirming instance must be a disconfirming instance..$^{37}$ )

Similarly, in court, three witnesses place Ms. Goodbody at the corner where a man was quietly stabbed on Tuesday, making a strong case for her conviction. ("Witness 1 says that Goodbody was there; Witness 2 says... So Goodbody is guilty.") The premises clearly "go together" since the agreement of the witnesses adds to the overall force of their testimony. Now when Witness 3 realizes that he was there not on Tuesday but rather on Monday and recants ("It is not the case that Witness 3 places Goodbody at the corner on Tuesday."), the case for the conclusion is weakened, but it is not destroyed. 
The courtroom model is clear and instructive. A jury in a criminal trial must disregard any unacceptable testimony presented by the prosecution. But the failure of that evidence does not mean that there is no case for conviction. And, correctly, we do not automatically reject any other sort of argument just on account of the falsity of some premise. Rather, we dismiss the unacceptable premises and evaluate the support for the conclusion on the basis of those that remain. We do not need a notion of convergent support to enable us to do this.

In some cases the falsity of a premise does mean that we must reject the whole argument. Diagrams constructed strictly by the relevance criterion exemplify when this is so. Since premises are (by definition) diagrammed as linked only when each requires the other to be relevant, the falsity of one results in the irrelevance of the others. And convergent premises are (by definition) those that remain relevant if the others are false.

We may well doubt that the fact that some premises are relevant without some others should be shown in diagrams. But deciding about the wisdom of showing or not showing "convergence" in this sense is just a matter of deciding on a "terminological" or "graphic" convention, at most a matter of convenience and practicality. We know, we have always known, that sometimes premises require others to be relevant to a conclusion. There is no conceptual issue at all here, much less an important one.

\section{9}

Supposedly, some sort of linked/ convergent distinction is "crucial to the analysis and evaluation of reasoning in natural language. $" 38$ We have not been able to see how this could be. In some formulations, the distinction falls on a scale between puzzling and incoherent. ${ }^{39}$ The "relevance criterion" and the "real criterion" make enough sense, but both are just instructions to construct diagrams in certain ways. They neither embody nor reflect a basic conceptual insight into the analysis or evaluation of arguments.

Advocates of the distinction point out that failing to consider premises together will have bad results, such as missing even instances of modus ponens. What bad results will come about from never thinking of arguments as convergent? We do not know. For centuries we got along well enough without the notion of "convergence." And we can do very well without it now.

\section{Notes}

I would like to thank John Parks-Clifford and Stephanie Ross for very astute and helpful comments on earlier versions of this paper.

1 Stephen Naylor Thomas, Practical Reasoning in Natural Language, Third Edition (Englewood Cliffs: Prentice-Hall, 1986), p. 60.

2 Thomas, p. 37.

3 This is a very slight variation on Thomas, p. 60 .

4 Thomas, p. 462.

5 Thomas, p. 457.
6 John Eric Nolt, Informal Logic: Possible Worlds and Imagination (New York: McGraw-Hill, 1984), p. 32.

7 Thomas, Practical Reasoning in Natural Language, Second Edition, p. 52. (All other references to Thomas are to the Third Edition.)

8 Basic Logic (St. Paul: West, 1988), p. 43. Cf. his article in the APA Newsletter on Teaching Philosophy 4 (1984), pp. 1-3. In the 1984 article, Yanal recommends abandoning the distinction. In the 1988 book he returns to it. I do not know why. (References to Yanal are to the book unless noted as $A P A$.) 
10 Yanal, p. 43.

11 Thomas, p. 62.

12 The Logic of Real Arguments, (Cambridge: Cambridge University Press, 1988), p. 19. Italics in the original.

13 Thomas, p. 60.

14 Thomas, p. 62. Why does he say "can be"? Could he mean that the application of his supposedly groundbreaking distinction is really optional, not mattering much one way or the other?

15 Thomas, p. 59.

16 A Practical Study of Argument, Second Edition (Belmont: Wadsworth, 1988), pp. 126, 129. Others who appear to be giving a linked/convergent distinction in terms of relevance include Lilly-Marlene Russow and Martin Curd, Principles of Reasoning (New York: St. Martin's, 1989), p. 17; James B. Freeman, Thinking Logically (Englewood Cliffs: PrenticeHall, 1988), p. 164; David Kelley, The Art of Reasoning (New York: Norton, 1988), pp. 86-87; Brooke Noel Moore and Richard Parker, Critical Thinking, Second Edition (Mountain View: Mayfield, 1989), pp. 204-5.

17 What if the premises are not relevant at all? Is an argument then neither linked nor convergent? Does this mean it is not really an argument? Should the distinction be put in terms of how premises are meant to be relevant? I suspect that following up on such questions will lead to another nest of insuperable problems for the convergent/linked distinction, but that would be a different story from the present one.

18 We might wonder whether those who give the clear, simple, "minimal" relevance criterion are even after whatever it is Thomas is after in his eight (plus appendix) pages of varying formulations and grandiose claims about the importance of the distinction. But they probably do mean to be after the same thing. Some (e.g., Govier) use the same terms ("linked" and "convergent"). Also, the examples they give of convergent arguments are much like Thomas's "going into business with Harry" example, cases where premises intuitively seem not just separately relevant but independent of one another in a stronger sense. This makes it appear that the relevance criterion is meant to pick out cases like these, although in fact it picks out these and many more.
19 Along with Govier (see examples (a), (b), and (c) on p. 99) and others, I will not usually fill out the enthymeme when, strictly speaking, there is one. "Nadine lays eggs" is relevant to "Nadine is a platypus" because of the unstated "Platypuses lay eggs."

20 This example is essentially the same as one Yanal uses to illustrate why (on his criterion) these premises should be diagrammed as linked (p. 55; cf. APA, p. 2). Yanal appears to be correct in saying that each of these premises is relevant to the conclusion without the other. Govier (pp. 126-27) mistakenly, I should think, suggests that in a similar case neither premise is relevant without the other. (I am not saying, of course, that each alternative of just any disjunction is equally likely. "Descartes was bearded or this is a 3 -sided square" is just one sort of case in which they are not.)

21 Thomas, p. 59.

22 Nolt, p. 90.

23 Nolt, p, 89.

24 This is what we would normally expect, but even it might not be correct in some cases. See section 5 above.

25 The qualification in note \#24 still applies.

26 Yanal, p. 54.

27 My colleague Ronald Munson tells me that rather severe electric shock does alleviate the effects of snakebite. If so, "separate lines of reasoning" about the bad effects of electric shock and about snakebite really could lead to needless death.

28 This differs from a) which said that all who die are cyclists.

29 Thomas, p. 59.

30 Yanal, $A P A$, p. 1.

31 Yanal, Basic Logic, pp. 42-43.

32 Yanal himself makes this point in the $A P A$ article (p. 2).

33 The left line leaves $20 \%$ uncertainty. The middle line reduces the $20 \%$ to $2 \%$ uncertainty. The right line reduces that to $8 \%$ uncertainty. So the conclusion is $99.2 \%$ likely if we reason in this way.

34 Unless some combination of premises yields a valid argument. Then they and any others will correctly "total" by the sharpshooter or any other method. (See section 4 above.) 
35 Yanal, p. 45.

36 Thomas, p. 65; see also p. 61.

37 See his chocolate bar example on p. 59.

38 Thomas, p. 462.
39 See section 2 above.

DAVID A. CONWAY

DEPARTMENT OF PHLLOSOPHY

UNIVERSITY OF MISSOURI-ST. LOUIS

ST. LOUIS, MO 6312I

\section{EDITORIAL INFORMATION}

\section{EDITORIAL POLICY: INFORMAL LOGIC} publishes articles which advance the dialectic in reasoning and argumentation in theory and practice, including but not restricted to: theory of argument, fallacy analysis and fallacy theory, criteria of good argument, rationality and argument, psychology of argumentation, argument fields, theory of critical thinking, the teaching of argumentation, informal logic and critical thinking, and related topics in cognate fields. Articles, reviews, and critical studies are blind refereed.

There are two related primary criteria for acceptance of articles with a theoretical focus or interest. First, the article should advance the dialectic or at the very least constitute an interesting comment on it. That is, it should cogently present an argument, objection, interpretation, or position that is an advance in relation to the historical background of issues and controversies; or else it should cast the issue addressed in a worthwhile new light.

Second, the article should touch base with the literature on its topic. It should use or mention pertinent literature and should discharge the burden of proof established by relevant items in that literature.

The primary criteria for acceptance of articles devoted to the teaching of informal logic, critical thinking, or argumentation include originality, utility, timeliness, and evidence of the effectiveness of proposed methods, materials, etc.

The standard criteria for scholarly publication-topic fit with the subjects covered by the journal, adequacy of coverage to the issue addressed, the clarity, organization, and literateness of the prose, and the conceptual clarity and cogency of its argumentationapply to all articles, notes, and reviews. Some of these criteria may be overridden if a paper has outstanding compensating features which warrant its publication.

MANUSCRIPT PREPARATION: Three copies required from Canada and USA (preferred from elsewhere), typewritten or nearletter-quality printed, double-spaced, one side only, minimum $2.5 \mathrm{~cm}(1 ")$ margins all around, on $21 \times 29.5 \mathrm{~mm}\left(8.5^{\prime \prime} \times 11^{\prime \prime}\right)$ bond paper. Copies should not be stapled but instead bound with paper clips. Notes and references, also doublespaced, should be on separate pages at the end of the manuscript. Symbols should be typewritercompatible. Diagrams, illustrations, or tables should preferably be professional-quality cameraready copy on separate sheets, with their location in the manuscript clearly indicated. Authors should not identify themselves on the manuscript, but only in an attached letter giving title and affiliation (if any) and complete mailing address. As well, overtly self-referential citations should normally be avoided. Manuscripts will not be returned unless sufficient Canadian or international postage is prepaid. (Authors should retain a copy.) Authors of accepted manuscripts will (1) be asked to send a copy of the final version in WordPerfect (preferably) or ASCII on a DOS floppy disk, as well as two hard copies; (2) be required to submit an abstract (maximum 100 words); (3) receive 10 offprints free and rights to reproduce additional copies.

All correspondence should be directed to: INFORMAL LOGIC

Department of Philosophy University of Windsor

Windsor, Ontario, Canada N9B 3P4

Phone: (519) 253-4232, ext. 2332

Fax: (519) 973-7050

Electronic mail: infolog@ucc.uwindsor.ca 